\title{
Dystrophic epidermolysis bullosa
}

INSERM

\section{Source}

INSERM. (1999). Orphanet: an online rare disease and orphan drug data base. Dystrophic epidermolysis bullosa. ORPHA:303

Dystrophic epidermolysis bullosa (DEB) is a form of inherited epidermolysis bullosa (EB) characterized by cutaneous and mucosal fragility resulting in blisters and superficial ulcerations that develop below the lamina densa of the cutaneous basement membrane and that heal with significant scarring and milia formation. It comprises ten sub-types with the three most common being generalized dominant DEB (DDEB), severe generalized recessive DEB (RDEB- sev gen) and RDEB generalized-other (see these terms). 